\title{
Functional neurosurgery in Parkinson's disease therapy
}

\author{
A Lavano \\ From de Senectute: Age and Health Forum \\ Catanzaro, Italy. 5-7 December 2009
}

During the last decade surgical therapy of Parkinson's disease has been considerably revalued and electrical stimulation techniques have taken the place of neurolesive techniques. Surgical therapy objective is not a direct solution of the illness cause but to control the symptoms responsible for serious daily life limitations.

Electrical stimulation techniques actually used in PD are Deep Brain Stimulation [1] and Motor Cortex Stimulation [2] Advantages of such techniques in comparison with neurolesive techniques are reversibility and adaptability.

Deep Brain Stimulation is indicated for patients with PD in which symptoms are not controlled by the pharmacological therapy or that suffer from L-Dopa serious collateral effects.

Stimulation system determines high frequency stimulation of anatomic-target structure of motor circuit with consequent functional block. Implanted system is formed by lead and pulse generator.

Lead can be stereotactly implanted, monolateral or bilateral, at level of: a) Subthalamic Nucleus for all predominant illness symptom control (tremor, rigidity and akinesia) and L-dopa induced dyskinesias; b) Internal Globus Pallidum for the control of the rigidity and of the dyskinesias, c) VIM Thalamus Nucleus for the exclusive control of tremor.

Motor Cortex Stimulation is a technique alternative to DBS indicated in advanced-complicated PD in cases of exclusion from DBS or of its ineffectiveness. Paddle lead is installed with neuronavigation system in epidural or subdural space beyond the motor area, controlaterally to the side where parkinsonian symptoms are prevailing. Stimulation effects are bilateral and stimulation is made with low frequency.

Neurosurgical DepartmentUniversity "Magna Graecia" of Catanzaro, Italy
Deep Brain Stimulation allows importing benefits suppressing PD symptoms, extending periods in which patient recovers normal and adequate functionality, reducing collateral effects induced by L-Dopa, improving quality of life and decreasing drugs intake.

Despite the still limited experience, Motor cortex stimulation is effective in a special way on axial symptoms and also on cognitive performances and autonomic signs.

Deep Brain Stimulation and Motor Cortex Stimulation are valid choices for advanced PD therapy. Advantages of such techniques in comparison with neurolesive techniques are safety, reversibility and adaptability.

\section{Published: 19 May 2010}

\section{References}

1. Benabid $A L$, Chabardes S: Deep brain stimulation of the subthalamic nucleus for the treatment of Parkinson's disease. Lancet Neurol 2009, 8(1):67-81.

2. Pagni CA, Cioni B, Lavano A, Mazzone P: Extradural Motor Cortex Stimulation (EMCS) for Parkinson's Disease. History and first results by the Study Group of the Italian Neurosurgical Society. Acta Neurochir Supp/ 2005, 93:113-119.

doi:10.1186/1471-2318-10-S1-L12

Cite this article as: Lavano: Functional neurosurgery in Parkinson's disease therapy. BMC Geriatrics 2010 10(Suppl 1):L12.

Submit your next manuscript to BioMed Central and take full advantage of:

- Convenient online submission

- Thorough peer review

- No space constraints or color figure charges

- Immediate publication on acceptance

- Inclusion in PubMed, CAS, Scopus and Google Scholar

- Research which is freely available for redistribution 